\title{
Updates in head and neck cancer: one year in review
}

\author{
Atualizações em câncer de cabeça e pescoço: revisão de um ano \\ Aline L. F. Chaves ${ }^{1,2}$, William N. William Jr ${ }^{1,3}$, Gustavo N. Marta ${ }^{1,4}$, Diego C. R. Morais ${ }^{1,5}$, Gilberto de Castro Jr ${ }^{1,4}$, Vinicius C. \\ Souza ${ }^{1,6}$, Eduardo D. de Moraes ${ }^{1,7}$, Thiago B. de Oliveira ${ }^{1,8}$, Luiz P. Kowalski ${ }^{1,8}$
}

\begin{abstract}
Introduction: Head and neck squamous cell carcinoma (HNSCC) encompass a heterogeneous group of tumors with a challenge treatment. In Brazil, HNSCC represent the third most frequent neoplasia in men. Aim: The aim of this study was to review the most relevant and practice changing articles recently published. Material and methods: The review of the literature covered studies published over the last year and described key evidence-based changes in treatment of HNSCC. Results: We retrieved nine studies with clinical impact. The main updates include: 1 ) systematic review in the treatment delivery time; 2) recommendations for the diagnosis of HPV oropharyngeal carcinoma; 3) guidelines for the delineation of target volumes in radiation therapy; 4) de-intensification of treatment in HPV positive oropharyngeal carcinoma; 5) induction chemotherapy; 6) immunotherapy. Conclusions: The treatment and diagnosis of HNSCC has changed over the last year, mainly with the inclusion of HPV positive oropharyngeal carcinoma and immunotherapy.
\end{abstract}

Keywords: Head and Neck Neoplasms; Carcinoma, Squamous Cell; Chemoradiotherapy; Immunotherapy; Patient Care Team

\footnotetext{
1. Grupo Brasileiro de Câncer de Cabeça e Pescoço and LACOG - Latin American Cooperative Oncology Group - Head and Neck, Head and Neck Oncology - São Paulo - SP - Brazil.

2. DOM Oncologia - Divinopolis - MG - Brazil.

3. Beneficência Portuguesa de São Paulo, Centro Oncológico - São Paulo - SP - Brazil.

4. Hospital Sírio Libanes - Sao Paulo, Instituto de Cancer do Estado de São Paulo - SP - Brazil.

5. Oncoclínicas Recife-PE and Hospital Santa Águeda, Caruaru - PE - Brazil.

6. Clínica AMO, Salvador - BA - Brazil.

7. Nucleo de Oncologia da Bahia - Grupo Oncoclínicas - Salvador - BA - Brazil.

8. AC Camargo Cancer Center - São Paulo - SP - Brazil.
}

\section{Financial support: none to declare.}

Conflicts of interest: ALFC: has received payments as a speaker, consultant, or in an advisory role from Bristol Meyers Squibb and Merck Serono. WNWJ: has received honoraria/speaker's fee and/or participated in advisory boards from Roche/Genentech, BMS, Eli Lilly, Merck, AstraZeneca, and Pfizer. TBO: as received payments as a speaker or in an advisory role from BMS - Bristol Meyers Squibb, MSD - Merck Sharp Dohme, Astra Zeneca, Bayer, Astellas, Janssen, Roche and Merck Serono. GNM: none to declare. VCS: as received payments as a speaker or consultant from Bayer, Janssen, Novartis, AstraZeneca, MSD, Dr Reddys, Roche, Janssen. Participation in clinical trials - BMS and Jansen. EDM: participation in clinical trials: BMS and Merck Serono. LPK: as received payments as a speaker from MSD. DCRM: none to declare. GCJ: C.J.: investigator of the KEYNOTE 048 trial, sponsored by MSD; consulting and advisory role for MSD, BMS; recipient of travel expenses and accommodations (MSD); member of speakers' bureau (AstraZeneca, MSD, BMS, Merck Serono

Corresponding author: Aline L. F. Chaves. GBCP: Grupo Brasileiro de Cancer de Cabeça e Pescoço. Av dos Andradas, 2287, s-709, Centro, Belo Horizonte, MG - Brazil. Zip-code: 30120-010. Email: alinelauda@hotmail.com 


\section{RESUMO}

Introdução: O carcinoma de células escamosas de cabeça e pescoço (CCECP) abrange um grupo heterogêneo de tumores com um tratamento desafiador. No Brasil, o CCECP representa a terceira neoplasia mais frequente em homens. Objetivo: $O$ objetivo deste estudo foi revisar os artigos mais relevantes publicados recentemente e que mudaram a prática. Material e métodos: A revisão da literatura abrangeu estudos publicados ao longo do último ano e descreveu as principais mudanças baseadas em evidências no tratamento do CCECP. Resultados: Foram recuperados nove estudos com impacto clínico. As principais atualizações incluem: 1) revisão sistemática do tempo do tratamento; 2 ) recomendações para o diagnóstico do carcinoma orofaríngeo por HPV; 3) diretrizes para o delineamento de volumes alvo em radioterapia; 4) desintensificação do tratamento em carcinoma de orofaringe positivo para HPV; 5) quimioterapia de indução; 6) imunoterapia. Conclusões: O tratamento e diagnóstico de CCECP mudaram ao longo do último ano, principalmente com a inclusão do carcinoma de orofaringe positivo para HPV e a imunoterapia.

Descritores: Neoplasias da Cabeça e Pescoço, Carcinoma de Células Escamosas, Quimioradioterapia, Imunoterapia, Equipe de Cuidado ao paciente.

\section{INTRODUCTION}

Head and neck squamous cell carcinomas (HNSCC) are the eighth most common malignancy, with 834.000 new cases diagnosed worldwide in $2018^{(1)}$. In Brazil, HNSCC are the third most frequent malignant neoplasia in men, with 14.700 new cases of oral cavity tumors and 7.670 new cases of laryngeal carcinoma diagnosed yearly(2). This paper reviews the most relevant studies published over the last year in head and neck oncology.

\section{MATERIAL AND METHODS}

We reviewed studies published over the last year and described key evidence-based changes in treatment of HNSCC. We focused in practice changing studies, not using a formal methodological tool.

\section{RESULTS}

We retrieved nine studies with clinical impact in head and neck oncology (Table 1).

Table 1. selected studies

\begin{tabular}{|c|c|c|}
\hline Author (year) & Study type & Subject \\
\hline Lewis et al. $(2018)^{6}$ & Guideline & HPV diagnosis in oropharyngeal carcinoma \\
\hline Grabovis et al.(2018) & Systematic Review & Treatment delivery time \\
\hline Grégoire et al. (2018)9 & \multirow{2}{*}{ Guideline } & \multirow{2}{*}{ Radiotherapy: delineation in target volume } \\
\hline Lee et al. $(2018)^{10}$ & & \\
\hline Gillison et al. $(2018)^{11}$ & Phase III - non-inferiority & \multirow{2}{*}{$\begin{array}{l}\text { HPV positive oropharyngeal carcinoma: treatment } \\
\text { deintensification }\end{array}$} \\
\hline Mehana et al. (2018) & Phase III & \\
\hline Ghi et al. $(2017)^{14}$ & Phase II/III & Induction chemotherapy \\
\hline Ferris et al. $(2018)^{18}$ & Phase III & Immunotherapy \\
\hline Burtness et al. $(2018)^{20}$ & Phase III & Immunotherapy \\
\hline
\end{tabular}




\section{Diagnosis}

\section{Human Papillomavirus Testing in Head and Neck Carcinomas: Guideline from the College of Ameri- can Pathologists}

Human papillomavirus (HPV) has been identified as a major cause of oropharyngeal squamous cell carcinomas (OPSCC) (3) and as a good prognostic marker ${ }^{(4)}$. HPV status is now integrated into the $8^{\text {th }}$ American Joint Committee on Cancer (AJCC) staging manual(5). The College of American Pathologists appointed an expert panel to develop an evidence-based set of recommendations ${ }^{(6)}$. Based on these guidelines, the major recommendations are: (1) testing newly diagnosed OPSCC patients for high-risk HPV, either from the primary tumor or from cervical nodal metastases, using p16 immunohistochemistry with a 70\% nuclear and cytoplasmic staining cutoff, and (2) not routinely testing non-squamous oropharyngeal carcinomas or nonoropharyngeal carcinomas for HPV. Pathologists should report tumors as HPV positive or p16 positive and follow the guidelines provided for testing cytologic samples and handling of locoregional and metastatic specimens.

\section{Treatment}

\section{Treatment delivery time}

Delays in the initiation or continuation of the oncological treatment are well established predictors of worse prognosis ${ }^{(7)}$. Recent systematic review confirmed the importance of the treatment delay in the management of head and neck tumors ${ }^{(8)}$. In this publication, after reviewing 13 studies, some of which have more than 20,000 patients and are published after 2015, the authors have shown that the delay in initiating the oncological treatment of head and neck cancers is associated with worse overall survival (OS). Delays in excess of 20 days would already be sufficient to compromise the final therapeutic outcome, although most studies agree that the optimal time to adjuvant treatment initiation is 46 to 52 days. The time from surgery to the initiation of postoperative radiotherapy was also evaluated in five studies all published in 2017 and 2018, two of them with more than 35,000 patients. The results indicate poorer oncologic outcomes in cases of delay exceeding 6 weeks for the initiation of radiotherapy, time interval recommended by NCCN (National Comprehensive Cancer Network) guideline and commonly used with quality indicator and benchmark target. Finally, the treatment package time (the time from surgery through the completion of postoperative radiotherapy) was analyzed in five studies, published from 2016 onwards, with a clear association between worse oncologic outcome and prolonged treatment package time. In summary, these data reinforce the importance of adopting measures that could provide the treatment initiation in a timely manner and minimize possibilities of dissolution of continuity of therapy.

\section{Radiation therapy \\ International guidelines for the delineation of target volumes}

Two international guidelines for the delineation of target volumes were published to describe a useful reference for correct contouring to certify ideal target coverage in oropharyngeal, hypopharyngeal, laryngeal, oral cavity and nasopharyngeal carcinoma. These guidelines contribute to decrease treatment differences in the regular radiation therapy practice, contribute to increase care of head and neck carcinoma patients and assist the conduct of clinical trials ${ }^{(9,10)}$.

\section{Systemic treatment}

\section{HPV positive oropharyngeal carcinoma: treatment deintensification: Concurrent radiation therapy with cisplatin or cetuximab}

Locally advanced, HPV-related, OPSCC have been recognized as a distinct entity, with a unique staging system, and a favorable prognosis when treated with concurrent chemoradiation therapy(5). Several efforts are under way to de-intensify care for this group of patients, aiming at preserving os with less short and long-term toxicities. One such strategy is the substitution of cetuximab for cisplatin, when given concurrently with radiation therapy. This was the study topic of two randomized trials published in 2018 - RTOG $1016^{(11)}$ and De-ESCALaTE ${ }^{(12)}$. In the non-inferiority RTOG 1016 trial, 849 patients with p16-positive T1-2, $\mathrm{N} 2 \mathrm{a}-3, \mathrm{MO}$ or T3-4, N0-3 MO HNSCC (AJCC $7^{\text {th }}$ edition) were randomly assigned to receive radiation therapy with concurrent cisplatin or cetuximab. The primary endpoint of OS favored the cisplatin over the cetuximab arm (85\% versus $78 \%$ alive at 5 years, respectively, HR 1.45, 1-sided 95\% upper confidence bound 1.94, $p=0.51$ for non-inferiority, $p=0.02$ for 1 -sided log-rank). Cetuximab-treated patients also had inferior progression-free survival and locoregional control. The acute toxicity profile, however, favored cetuximab, as assessed by the T-score method. The De-ESCALaTE trial showed similar results. With 334 low-risk, p16-positive HNSCC patients randomized between radiation therapy given concurrently with cisplatin or cetuximab, the trial failed to meet its primary endpoint of overall severe (grade $3-5)$ toxicity rate $(4.8 \%$ for cisplatin, $4.8 \%$ for cetuximab), while showing inferior 2-year OS for the cetuximab arm (89.4\% versus $97.5 \%$ for cisplatin, HR 4.99, 95\% Cl 1.70-14.67, $\mathrm{P}=0.001)$. Locoregional and distant recurrence rates were also higher for cetuximab-treated patients. Even within a more favorable subgroup of patients excluding T4 or N3 disease, the OS favored cisplatin. Taken together, these results demonstrate the importance of conducting prospective, randomized trials within the context of treatment de-intensification for HPV-related HNSCCS before implementation in routine clinical practice and support concurrent cisplatin and radiation therapy as the standard of care treatment option in this setting. 


\section{Induction chemotherapy}

The efficacy of induction chemotherapy followed by chemoradiation (CCRT) compared to CCRT alone has not been consistently demonstrated in randomized clinical trials. Finally, a phase II/III, a two-by-two factorial randomized, multicentric Italian trial was the first to show a significant OS benefit for induction chemotherapy, though with a borderline improvement in loco-regional control (LCR) ${ }^{(13)}$. Patients treated with a modified dose of docetaxel, cisplatin and 5-FU (TPF) had a median OS of 54.7 months versus 31.7 months $(H R=0.73 ; p=0.0029)^{(14)}$. Strengths of this study was the number of accrued subjects $(\mathrm{N}=421)$ and weak points was the more complicated factorial design, high number of patients with primary tumors of the oral cavity and lack of HPV status of oropharyngeal tumors. This trial must be seen with caution because, recently, three phase III trials failed to demonstrate a survival benefit for the addition of IC to CCRT (14-16). Despite this positive result, induction chemotherapy treatment must be considered investigational and only very selected patients should be treated with induction chemotherapy (younger patients, excellent performance status, high risk of recurrence (i.e: N2/N3, specially HPV negative disease).

\section{Immunotherapy}

Immunotherapy is consolidated as standard of care second line treatment for recurrent or metastatic head and neck cancer, after failure of platinum-based therapy, and in 2018 the updated results of one of the pivotal phase 3 trials in this field were published. The Checkmate 141 trial randomized 361 patients with recurrent or metastatic head and neck squamous cell carcinoma, whose disease had progressed within 6 months of platinum-based chemotherapy to receive, in a 2:1 ratio, nivolumab versus investigator choice of therapy (IC: docetaxel or methotrexate or cetuximab)(17). The two-year update, with a minimum follow up of 24.2 months confirmed the initial results and showed that nivolumab $(n=240)$ continued to improve OS over IC $(n=121)$, with a hazard ratio (HR) of $0.68(95 \% \mathrm{Cl} 0.64-0.86)$, and a median OS of 7.7 months for nivolumab versus 5.5 months for $\mathrm{IC}^{(18)}$. Nivolumab was associated with an estimated 24 -month OS rate of $16.9 \%$ versus $6 \%$ for IC, and demonstrated OS benefit across patients with tumor PD-L1 expression $\geq 1 \%$ ( $\mathrm{HR}=0.55 ; 95 \% \mathrm{Cl}$ : 0.39-0.78) or $<1 \%(\mathrm{HR}=0.73 ; 95 \% \mathrm{Cl}: 0.49-1.09)$ and patients HPV positive ( $\mathrm{HR}=0.60 ; 95 \% \mathrm{Cl}$ : $0.37-0.97)$ or negative $(\mathrm{HR}=0.59 ; 95 \% \mathrm{Cl}: 0.38-0.92)$. In the nivolumab arm, there were no observed differences in baseline characteristics between long-term survivors and the overall population. With a long-term follow-up, safety profile remained favorable to nivolumab compared to IC, with fewer grade 3-4 treatment related adverse events (TRAEs) in the nivolumab arm (15.5\%) compared to IC (36.9\%). Immune related adverse events incidence was consistent with previous analyses, with the majority of grade 3-4 events in the nivolum$\mathrm{ab}$ arm occurring in the first 6 months of treatment. It is also worth noticing that, in an exploratory analysis of this trial, nivolumab stabilized quality of life parameters like symptoms and functioning, whereas IC led to clinically meaningful deterioration ${ }^{(19)}$. These results established Nivolumab as a therapeutic option for post-platinum recurrent or metastatic head and neck cancer.

KEYNOTE 048 is an open-label, randomized phase 3 trial with 3 arms, comparing the standard of care chemotherapy regimen cetuximab, cisplatin and fluorouracil (PFE, known as EXTREME regimen) versus pembrolizumab (I) 200mg q3w alone or in combination with chemotherapy (cisplatin and fluorouracil, $\mathrm{PF}+\mathrm{I})$ for patients with recurrent or metastatic head and neck squamous cell carcinoma (R/M HNSCC) as first-line systemic therapy. Primary endpoints were OS and progression-free survival (PFS). During European Congress of Medical Oncology (ESMO) Congress 2018, the results of the second interim analysis were presented, with 882 patients randomly allocated ${ }^{(20)}$. Subgroup analysis considered the combined positive score (CPS) $\geq 20$ or $\geq 1$. The trial was positive and pembrolizumab was superior to PFE in terms of OS in CPS $\geq 20$ (median 14.9 vs 10.7 months; $P$ $=0.0007$ ) and in the CPS $\geq 1$ patients (median 12.3 vs 10.3 months; $P=0.0086$ ). It did not prolong PFS in $C P S \geq 20(P=0.5)$; and per the analysis plan, no further PFS testing was done for I vs PFE. PF + I was non-inferior and superior to PFE for OS in the total population (median 13.0 vs 10.7 months; $P=0.0034$ ). The median duration of response was remarkably better in those patients who received pembrolizumab alone, with 20.9 months vs. 4.2 months to PFE arm in CPS $\geq 20$. The rate of grade 3-4 adverse effects (AEs) was $17 \%$, in patients receiving pembrolizumab alone, was $69 \%$ in the PFE arm and $71 \%$ for PF+I. Pembrolizumab associated with chemotherapy can be now considered as the new standard first line treatment in those patients with R/M HNSCC. Pembrolizumab alone may be considered for selected patients with CPS $\geq 20$ or $\geq 1$, taking into account the low response rate of this therapeutic option.

\section{DISCUSSION/CONCLUSIONS}

The last year provided physicians who treat patients with head and neck cancer with significant new data on diagnosis, staging and treatment. Including these new data in Brazilian health care reality is essential and a challenge. Classifying oropharyngeal carcinoma patients in HPV positive or negative is important in public and private scenario, although it doesn' $t$ change the treatment. Despite the better prognosis in patients with OPSCC (at least in patients from developed countries), the treatment cannot be 
de-intensified with the available studies. Two robust trials demonstrated the strategy to substitute cetuximab for cisplatin in patients with HPV positive OPSCC worsens patient's prognosis. The classical treatment of advanced HNSCC should be kept: concurrent cisplatin with radiation therapy. The positive results of the induction Italian trial raises the question induction chemotherapy can be used in high risk patients. Lastly, the new era of immunotherapy comes to head and neck cancer treatment: nivolumab for recurrent or metastatic HNSCC patient's cisplatin refractory and pembrolizumab for patients in first line treatment. Immunotherapy demonstrated better survival with better tolerance than classical chemotherapy. The Brazilian challenge will be providing access to these new treatments for all patients who needs it in spite of the limited resources for medical care in the public system. Timely and multiprofessional care, following current guidelines, can offer better survival with lower cost in the Brazilian scenario.

\section{REFERENCES}

1. Bray F, Ferlay J, Soerjomataram I, Siegel RL, Torre LA, Jemal A. Global Cancer Statistics 2018: GLOBOCAN Estimates of Incidence and Mortality Worldwide for 36 Cancers in 185 Countries. CA Cancer J Clin. 2018;68(6):394-424.

2. Brazil. Ministry of Health. Instituto Nacional de Câncer José Alencar Gomes da Silva - INCA. Coordenação de Prevenção e Vigilância. Estimate 2018: Cancer Incidence in Brazil. Rio de Janeiro: INCA; 2017. [In Portuguese].

3. Marur S, D'Souza G, Westra WH, Forastiere AA. HPV-associated head and neck cancer: a virus-related cancer epidemic. Lancet Oncol. 2010;11(8):781-9.

4. Ragin CCR, Taioli E. Survival of squamous cell carcinoma of the head and neck in relation to human papillomavirus infection: review and meta-analysis. Int J Cancer. 2007;121(8):1813-20.

5. Amin MB, Edge SB, Greene F, Byrd DR, Brookland RK, Washington MK, et al., eds. AJCC Cancer Staging Manual. 8th ed. New York: Springer; 2017

6. Lewis JS, Beadle B, Bishop JA, Chernock RD, Colasacco C, Lacchetti C, et al. Human Papillomavirus Testing in Head and Neck Carcinomas: Guideline From the College of American Pathologists. Arch Pathol Lab Med. 2018;142(5):559-97.

7. Murphy CT, Galloway TJ, Handorf EA, Egleston $B L$, Wang LS, Mehra R, et al. Survival Impact of Increasing Time to Treatment Initiation for $\mathrm{Pa}$ tients With Head and Neck Cancer in the United States. J Clin Oncol. 2016;34(2):169-78.

8. Graboyes EM Kompeli AR, Neskey DM, Brennan E, Nguyen S, Sterba KR, et al. Association of treatment delays with survival for patients with head and neck cancer: a systematic review. JAMA Otolaryngol Head Neck Surg. 2018 Nov 1. DOI: 10.1001/jamaoto.2018.2716. [Epub ahead of print]

9. Grégoire V, Evans M, Le QT, Bourhis J, Budach V, Chen $A$, et al. Delineation of the primary tumour Clinical Target Volumes (CTV-P) in laryngeal, hypopharyngeal, oropharyngeal and oral cavity squamous cell carcinoma: AIRO, CACA, DAHANCA, EORTC, GEORCC, GORTEC, HKNPCSG, HNCIG, IAG-KHT, LPRHHT, NCIC CTG, NCRI, NRG Oncology, PHNS, SBRT, SOMERA, SRO, SSHNO, TROG consensus guidelines. Radiother Oncol. 2018;126(1):3-24.

10. Lee AW, Ng WT, Pan J, Poh SS, Ahn YC, AlHussain $\mathrm{H}$, et al. International guideline for the delineation of the clinical target volumes (CTV) for nasopharyngeal carcinoma. Radiother Oncol. 2018;126(1):25-36.

11. Gillison ML, Trotti AM, Harris J, Eisbruch A, Harari PM, Adelstein DJ, et al. Radiotherapy plus cetuximab or cisplatin in human papillomavirus-positive oropharyngeal cancer (NRG Oncology RTOG 1016): a randomised, multicentre, non-inferiority trial. Lancet. 2018. pii: S0140-6736(18)32779-X.

12. Mehanna $H$, Robinson $M$, Hartley $A$, Kong $A$, Foran B, Fulton-Lieuw T, et al.; De-ESCALaTE HPV Trial Group. Radiotherapy plus cisplatin or cetuximab in low-risk human papillomavirus-positive oropharyngeal cancer (De-ESCALaTE HPV): an open-label randomised controlled phase 3 trial. Lancet. 2018. pii: S0140-6736(18)32752-1.

13. Ghi MG, Paccagnella A, Ferrari D, Foa P, Alterio D, Codecà C, et al.; GSTTC (Gruppo di Studio Tumori della Testa e del Collo) Italian Study Group. Induction TPF followed by concomitant treatment versus concomitant treatment alone in locally advanced head and neck cancer. A phase II-III trial. Ann Oncol. 2017;28(9):2206-12.

14. Haddad R, O'Neill A, Rabinowits G, Tishler R, Khuri F, Adkins D, et al. Induction chemotherapy followed by concurrent chemoradiotherapy (sequential chemoradiotherapy) versus concurrent chemoradiotherapy alone in locally advanced head and neck cancer (PARADIGM): a randomised phase 3 trial. Lancet Oncol. 2013;14(3):257-64.

15. Cohen EE, Karrison TG, Kocherginsky M, Mueller J, Egan $\mathrm{R}$, Huang $\mathrm{CH}$, et al. Phase III randomized trial of induction chemotherapy in patients with N2 or N3 locally advanced head and neck cancer. J Clin Oncol. 2014;32(25):2735-43. 
16. Hitt R, Grau JJ, López-Pousa A, Berrocal A, GarcíaGirón C, Irigoyen A, et al.; Spanish Head and Neck Cancer Cooperative Group (TTCC). A randomized phase III trial comparing induction chemotherapy followed by chemoradiotherapy versus chemoradiotherapy alone as treatment of unresectable head and neck cancer. Ann Oncol. 2014;25(1):216-25.

17. Ferris RL, Blumenschein G Jr, Fayette J, Guigay J, Colevas AD, Licitra $L$, et al. Nivolumab vs investigator's choice in recurrent or metastatic squamous cell carcinoma of the head and neck: 2-year long-term survival update of CheckMate 141 with analyses by tumor PD-L1 expression. Oral Oncol. 2018;81:45-51.
18. Ferris RL, Blumenschein G Jr, Fayette J, Guigay J, Colevas $A D$, Licitra $L$, et al. Nivolumab for Recurrent Squamous-Cell Carcinoma of the Head and Neck. N Engl J Med. 2016;375(19):1856-67.

19. Harrington $\mathrm{KJ}$, Ferris $\mathrm{RL}$, Blumenschein $\mathrm{G} J \mathrm{r}$, Colevas AD, Fayette J, Licitra L, et al. Nivolum$a b$ versus standard, single-agent therapy of investigator's choice in recurrent or metastatic squamous cell carcinoma of the head and neck (CheckMate 141): health-related quality-of-life results from a randomised, phase 3 trial. Lancet Oncol. 2017;18(8):1104-15.

20. Burtness B, Harrington KJ, Greil R, et al. First-line pembrolizumab for recurrent/metastatic head and neck squamous cell carcinoma (R/M HNSCC): interim results from the phase 3 KEYNOTE-048 study. Ann Oncol. 2018;29(Suppl 8):729. 